\title{
Toll-like receptor-2 deficiency enhances non-alcoholic steatohepatitis
}

\author{
Chantal A Rivera*1,2, LaTausha Gaskin¹, Monique Allman'1, Jia Pang ${ }^{1}$, Kristen Brady¹, Patrick Adegboyega' and \\ Kevin Pruitt ${ }^{1}$
}

\begin{abstract}
Background: Previously we reported that mice deficient in toll-like receptor 4 (TLR-4) signalling were protected from diet-induced non-alcoholic steatohepatitis (NASH). Another member of the toll-like receptor family, TLR-2, has been shown to play a role in lipid trafficking via uptake of diacylated lipoproteins. However, a role for TLR-2 in NASH has not been elucidated. The objectives of the current study were to examine the influence of dietary fat quality and TLR-2 on NASH pathogenesis.

Methods: Steatohepatitis was induced in male Db, C57BL/6 and TLR-2that was deficient in methionine and choline (MCDD). Mice fed the base diet supplemented with methionine and choline (control diet; CD) were used as controls. To determine the role of fat quality, MCDD was enriched with polyunsaturated corn oil (PUFA) or coconut oil that is comprised mostly of saturated fat (SAFA); the total amount of each fat was $112.9 \mathrm{~g} / \mathrm{kg}$ of diet. After 8 weeks of feeding CD or MCDD, hepatic steatosis, inflammation and necrosis were evaluated in histological sections. Total RNA was extracted from frozen liver samples and mRNA expression of TNFa, collagen a1, IL-10, peroxisome proliferator-activated receptor- $\gamma$ (PPAR- $\gamma$ ), TLR-4, and CD14, was analyzed via realtime PCR. Protein levels of TLR-2 were analyzed by western blot.

Results: Panlobular macrovessicular steatosis and diffuse leukocyte infiltration were noted in PUFA-fed Db mice. Histological scores demonstrated significantly less steatosis, inflammation and necrosis in SAFA-fed mice of all mouse strains. However, compared to wild type mice, hepatocellular damage was notably more severe in TLR-2-/- mice. Consistent with histological findings, mRNA expression of TNFa was elevated by approximately 3 -fold in TLR-2-- mice; PPAR- $y$ expression was blunted in this strain compared to wild type. Expression of the matrix protein collagen al was also significantly higher in TLR-2-- mice, indicating a pro-fibrogenic state. Sensitivity to steatohepatitis due to dietary fat or TLR-2 deficiency correlated significantly with alterations in the expression of TLR-4 as well as the co-receptor CD-14.

Conclusions: Our findings suggest that dietary saturated fat plays a protective role against MCDD-induced steatohepatitis, whereas TLR-2 deficiency exacerbated NASH. The mechanism underlying the response to dietary fat and TLR-2 likely involves altered signalling via the TLR-4 pathway.
\end{abstract}

\section{Background}

For more than a decade the worldwide proportion of obese individuals has increased yearly. Along with rates of obesity, the incidence of co-morbid conditions such as type 2 diabetes, cardiovascular disease and liver disease have also increased. Non-alcoholic steatohepatitis (NASH) is a form of liver disease associated with obesity, and is characterized by the accumulation of lipid droplets

* Correspondence: crive1@lsuhsc.edu

1 Department of Molecular and Cellular Physiology, Louisiana State University Health Sciences Center, Shreveport, LA USA

Full list of author information is available at the end of the article in the cytoplasm of hepatocytes, mixed cell type inflammation, necrosis and often may involve some degree of fibrosis. The prevalence of NASH is reportedly as high as $40-100 \%$ of obese patients in some studies [1]. Initiating factors and underlying mechanisms of progression of this type of liver disease have not yet been elucidated.

The degree of adiposity in humans is attributed primarily to poor lifestyle habits such as excessive caloric intake. As a result, recent investigations have focused on elucidating the contribution of diet to the development of systemic pathologies. A positive correlation has been found 
to exist between the incidence of metabolic syndrome and the amount of total dietary fat intake of obese humans. One of the major constituents of the "western" diet (WD) typically consumed in the United States is saturated fat. A study using a simulation model based on hypothesized dietary changes reported that decreasing daily intake of saturated fat by 5 grams would reduce the number of obese people by 3.9 million, thereby markedly reducing costs of obesity-associated healthcare [2]. Indeed, the content of saturated fat correlates positively with the incidence of several co-morbid conditions such as type 2 diabetes and cardiovascular disease [3-7]. Studies performed in vitro have demonstrated the ability of saturated fatty acids to directly stimulate a pro-inflammatory phenotype [8-11], which likely contributes to disease pathogenesis. For example, addition of the saturated fatty acids palmitate and stearate to cultures of human pancreatic islets elicited the production of various pro-inflammatory cytokines and chemokines [12]. Palmitate similarly stimulated inflammation in endothelial cells [5]. Further studies in various cell types, including endothelial cells as well as macrophage cell lines, indicate that the observed inflammatory response is mediated by signalling via the toll-like receptor (TLR) pathway [10,13].

The TLR family of pattern recognition receptors is critical in host defence against invading pathogens. Of the approximately 13 mammalian TLRs, TLR-4 and TLR-2 have been studied extensively in the setting of obesityassociated inflammation and disease pathogenesis. These receptors respond to gram negative and gram positive organisms, respectively. Recently, we reported that mice deficient in TLR-4 signalling due to a spontaneous mutation were protected from diet-induced NASH [14]. Depletion of Kupffer cells via administration of liposome encapsulated clodronate significantly reduced TLR-4 expression and similarly blunted steatohepatitis. TLR-2 has been shown to play a role in lipid trafficking via uptake of diacylated lipoproteins [15], a process that requires CD36 [16]. Although a significant role for TLR-4 signalling in the progression of NASH has been established, a role of the closely-related TLR-2 pathway remains to be determined.

The focus of the present study was to investigate the potential interactions between dietary fat quality and TLR signalling. The major objectives were to 1) examine the influence of saturated fat relative to polyunsaturated fat; and 2) investigate the importance of TLR-2 in the pathogenic mechanisms underlying NASH. To this end, we compared the extent of steatohepatitis in wild type and TLR-2 deficient mice fed a methionine and choline deficient diet (MCDD) enriched with polyunsaturated corn oil or coconut oil as the saturated fat. In this model hepatic microvascular dysfunction and pronounced pathological changes develop within 3-4 weeks [17-19]. Based on previous findings of the pro-inflammatory roles of saturated fat and TLR-2 signalling that adversely effect the vasculature, we hypothesized that feeding saturated fat as the primary fat source would exacerbate NASH and that TLR-2 deficiency would protect against NASH pathogenesis.

\section{Methods}

\section{Animal treatment}

Male $\mathrm{Db}$ and C57BL/6 mice were purchased from Jackson laboratories at 4-6 weeks of age. The TLR-2/- mice were initially a gift from A. Akira (Tokyo, Japan) and were back-crossed on to the C57BL/6 background for 8 generations. Steatohepatitis was induced by feeding an Lamino acid-defined diet that was deficient in methionine and choline (MCDD). The base diet supplemented with methionine and choline was used as a control diet (CD). As outlined in Table 1, the MCDD diets were enriched with 112.9 grams of coconut oil (SAFA) or corn oil (PUFA). Mice were fed ad libitum for 8 weeks. The protocols used for handling mice were approved by the Louisiana State University Health Sciences Center Animal Care Committee and were in accordance with the guidelines set by the National Institutes of Health Guide for Care and Use of Laboratory Animals.

\section{Assessment hepatic injury}

After 8 weeks of feeding, a small section of each liver was preserved in zinc-buffered fixative and sections were stained with hematoxylin and eosin to assess hepatic injury. Steatosis, inflammation and necrosis were scored by one of the authors (P. A.) that was blinded to the study design. The absence of these histopathological features was scored as 0 and the most severe changes were given a score of 3 .

\section{Reverse transcription and real-time PCR}

Total RNA was extracted from frozen liver samples using the Qiagen RNeasy reagents. Each total RNA sample (500 ng) was reverse transcribed using TaqMan transcription buffer and multiscribe reverse transcriptase (Applied Biosystems; Foster City, CA). The relative mRNA expression of TNF $\alpha$, IL-10, peroxisome proliferator-activated receptor- $\gamma$ (PPAR- $\gamma$ ), collagen $\alpha 1$, TLR-4, and CD14 was analyzed using pre-developed assays for real-time PCR (Applied Biosystems). In a separate tube, ribosomal 18s was amplified as a reference. Gene expression was quantified using a comparative critical threshold $\left(C_{\mathrm{T}}\right)$ method as described previously [20].

\section{Western blotting}

Total protein $(50 \mu \mathrm{g})$ was separated by gel electrophoresis and transferred to polyvinylidene fluoride membranes. Membranes were blotted with antibodies directed against 
Table 1: Dietary Components.

\begin{tabular}{lccc}
\hline Ingredient (g/Kg) & Control Diet & PUFA Diet & SAFA Diet \\
\hline Cornstarch & 419.1 & 384.7 & 140.7 \\
\hline Dyetrose & 140 & 140 & 100 \\
\hline Sucrose & 100 & 100 & 50 \\
\hline Cellulose & 50 & 50 & 112.9 \\
\hline oil & 70 & 112.9 & 35 \\
\hline Salt Mix \#210030 & 35 & 35 & 6.4 \\
\hline Sodium Bicarbonate & 6.4 & 6.4 & 10 \\
\hline Vitamin Mix\#310025 & 10 & 10 & 0 \\
\hline Choline Bitartrate & 2.5 & 0 & 35 \\
\hline
\end{tabular}

TLR-2 ( $4^{\circ} \mathrm{C}$ overnight; Cell Signalling Technology; Danvers, MA) or $\beta$-actin ( $1 \mathrm{~h}$ at ambient temperature; $\mathrm{BD}$ Biosciences) then incubated with an isotype-specitific HRP-conjugated secondary antibody ( $1 \mathrm{~h}$ at ambient temperature). Target proteins were visualized using extended duration substrate detection reagents (Pierce) in a Chemidoc XRS documentation system (Bio-Rad Laboratories; Hercules, CA).

\section{Data Analysis}

Statistical analysis was performed on histological scores using ANOVA on Ranks; the remaining data was analyzed using two-way ANOVA with $\mathrm{p}<0.05$ as the level of significance. For each parameter tested, $n=6$ observations per group were analyzed.

\section{Results}

Effect of feeding unsaturated or saturated fat-enriched diet on steatohepatitis

The goal of the first set of experiments was to determine the extent of NASH pathogenesis in Db mice fed corn oilenriched PUFA diet or SAFA that was enriched in coconut oil as the fat source. To induce robust features of $\mathrm{NASH}$, both diets were deficient in methionine and choline. Panlobular macrovessicular steatosis and diffuse leukocyte infiltration was noted in PUFA-fed mice (Fig. 1). Histological findings were comparably less severe in the SAFA group. In fact, injury in this group was limited pri- marily to zone 3. A summary of the histological scores is presented in Figure 1B; the pathology observed was highly reproducible with minimal inter-animal variation. These scores demonstrate significantly less steatosis, inflammation and necrosis in SAFA-fed mice.

\section{Effect of diet on TNF- $a$ and collagen a 1 expression}

To index inflammation and fibrosis, mRNA expression of TNF $-\alpha$ and collagen $\alpha 1$ (Fig. 2) were measured using quantitative real-time PCR. Compared to $\mathrm{Db}$ mice fed $\mathrm{CD}$, there was an approximately 6 -fold increase in TNF- $\alpha$ and collagen in PUFA-fed mice. Increases in both of these parameters were prevented in mice that were fed SAFA.

\section{Effect of diet on toll-like receptor-4}

We showed previously that TLR-4 signalling was critical for NASH pathogenesis [14]. In an attempt to determine if differences in TLR-4 expression might explain the blunted injury in mice fed SAFA, mRNA expression of TLR-4 and the co-receptor CD14 was examined. As expected, expression of TLR-4 and CD14 was enhanced significantly by approximately 2.5 -fold and 20-fold, respectively, in mice fed the PUFA diet (Fig. 3). In contrast, feeding SAFA blunted increases in mRNA levels of both TLR-4 and CD14.

\section{Effect of diet on toll-like receptor-2}

Next, the influence of diet on the expression of TLR-2 was investigated. Western blot analysis revealed a dra- 
A.
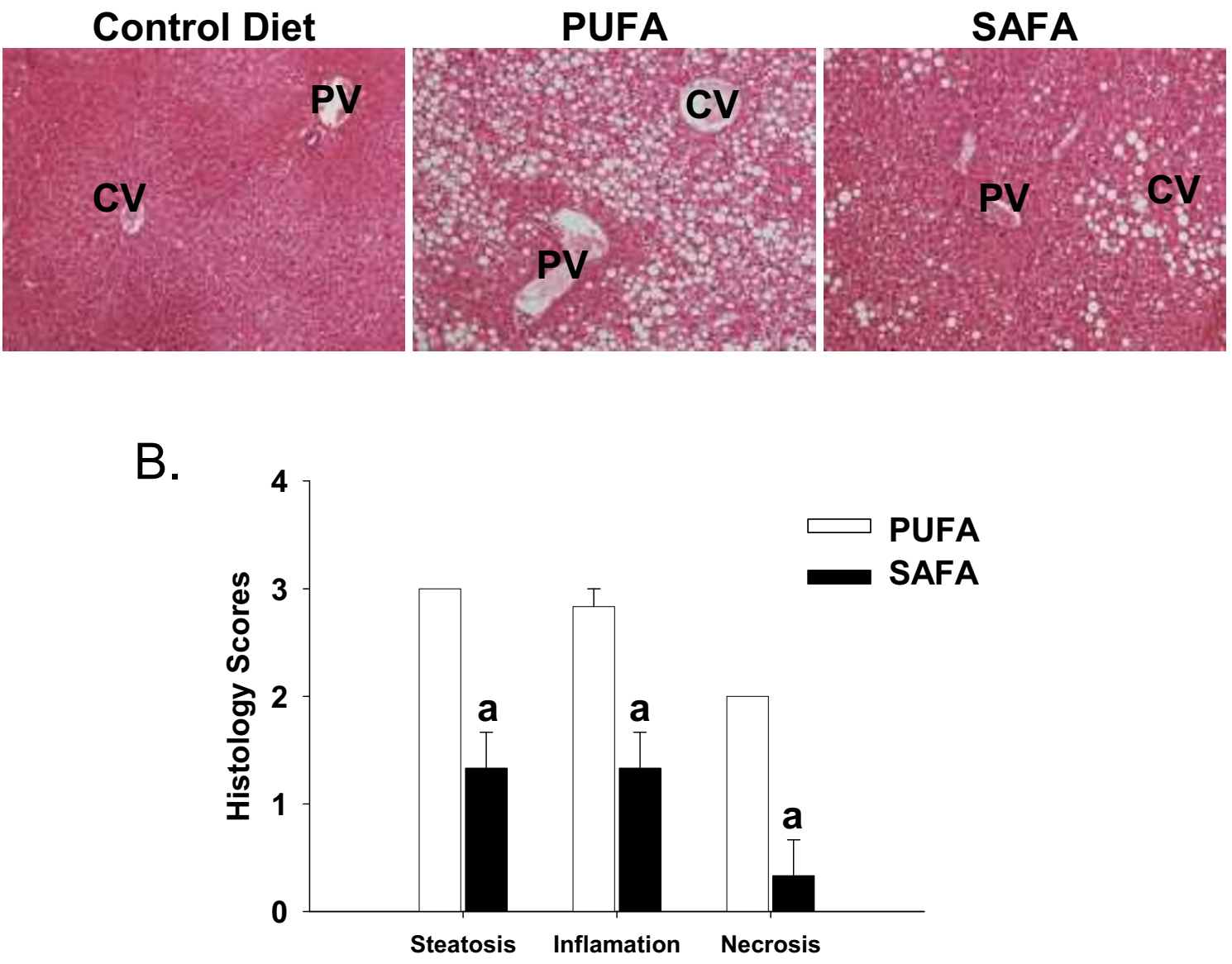

Figure 1 Hepatic histopathology. (A). Representative H\&E-stained photomicrographs of livers obtained from Db mice after 8 weeks of feeding control diet (CD), corn oil diet (PUFA) or coconut oil diet (SAFA). PV = portal vein; $C V=$ central vein. (B) Summary of histology scores. The following scoring system was used for each parameter. 1 = mild; $2=$ moderate; $3=$ severe. Original magnification $=20 \times$. Data was analyzed using Student's $t$ test; ${ }^{2} p<$ 0.05 compared to PUFA.

matic reduction in protein levels of TLR-2 in PUFA-fed mice (Fig. 4). As summarized in Figure 4, the reduction in TLR-2 expression was markedly attenuated in mice fed the SAFA diet.

\section{Effect of diet on Steatohepatitis in TLR-2-/- mice}

Based on the opposing effects of the PUFA and SAFA diets on protein levels of TLR-2, subsequent experiments were designed to investigate what role TLR-2 might play in NASH pathogenesis. In this series of experiments C57BL/6 wild type and TLR-2/- mice were fed PUFA or SAFA for 8 weeks. Similar to findings in Db mice, C57BL/ 6 wild types fed PUFA displayed histological evidence of steatosis and injury (Fig. 5). These features were markedly reduced in SAFA-fed wild type mice (Fig. 5). Feeding either of these methionine/choline-deficient diets exaggerated NASH in TLR-2 $\%$ mice, resulting in panlobular steatohepatitis.
Enhanced expression of inflammatory and fibrosis markers in toll-like receptor-2 deficient mice

Messenger RNA expression of the proinflammatory cytokine TNF- $\alpha$ as well as the anti-inflammatory cytokine IL-10 was assessed by real-time PCR to index the hepatic inflammatory state. Expression of TNF- $\alpha$ was similar among wild type and TLR-2/- mice fed PUFA (Fig. 6). In SAFA-fed mice, mRNA expression of this cytokine was higher by approximately 3 -fold in TLR- $2 \%$ mice compared to diet-matched wild type mice. Feeding MCDD to wild type mice diminished IL-10 expression irrespective of the type of fat included in the diet (Fig. 6). In CD-fed mice, expression of this cytokine in TLR- $2^{-/}$mice was approximately 3 -fold lower than wild types; feeding MCDD had no further effect on IL-10 expression in the TLR-2 deficient mouse strain.

Similar to TNF- $\alpha$, mRNA levels of the matrix protein collagen $\alpha \mathrm{I}$, a marker of hepatic fibrogenic potential, was 

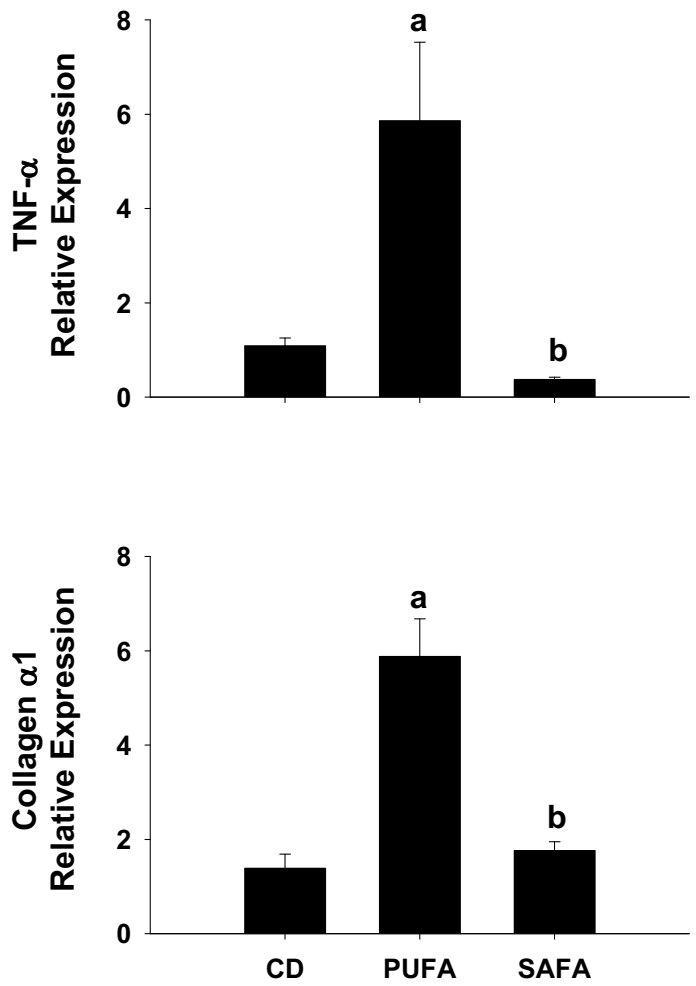

Figure 2 Hepatic TNF- $a$ and Collagen mRNA levels. Expression of TNF-a and Collagen a1 mRNA was analyzed by real-time PCR and calculated relative to average values of mice fed control diet (CD) using a comparative $C_{T}$ method. Data are presented as mean \pm SEM of 4 observations/group. Statistical comparisons were made using one-way ANOVA. ap $<0.05$ compared to mice fed $C D$; $b p<0.05$ compared to mice fed PUFA.

highest in PUFA-fed mice of both strains; however TLR-2 deficiency significantly enhanced expression in mice fed SAFA when compared to diet-matched wild types (Fig. 7). To further index the response to diet and TLR-2 deficiency, mRNA levels of PPAR- $\gamma$ were assessed. This receptor has been shown to have anti-inflammatory properties and to blunt fibrogeneis via regulation of stellate cell activation. Expression of this receptor was enhanced significantly in wild type mice fed SAFA (Fig. 7). Consistent with increased inflammation and fibrogenic potential observed in TLR $-2^{-}$mice, PPAR- $\gamma$ expression in this mouse strain was significantly lower than diet-matched wild type mice fed PUFA or SAFA.

\section{Toll-like receptor- 4 signalling is augmented in toll-like receptor-2 deficient mice}

To investigate activation of TLR-4 signalling, mRNA expression of components of the TLR-4 pathway were quantified via real-time PCR. Consistent with findings in the $\mathrm{Db}$ strain, SAFA attenuated the expression of TLR-4

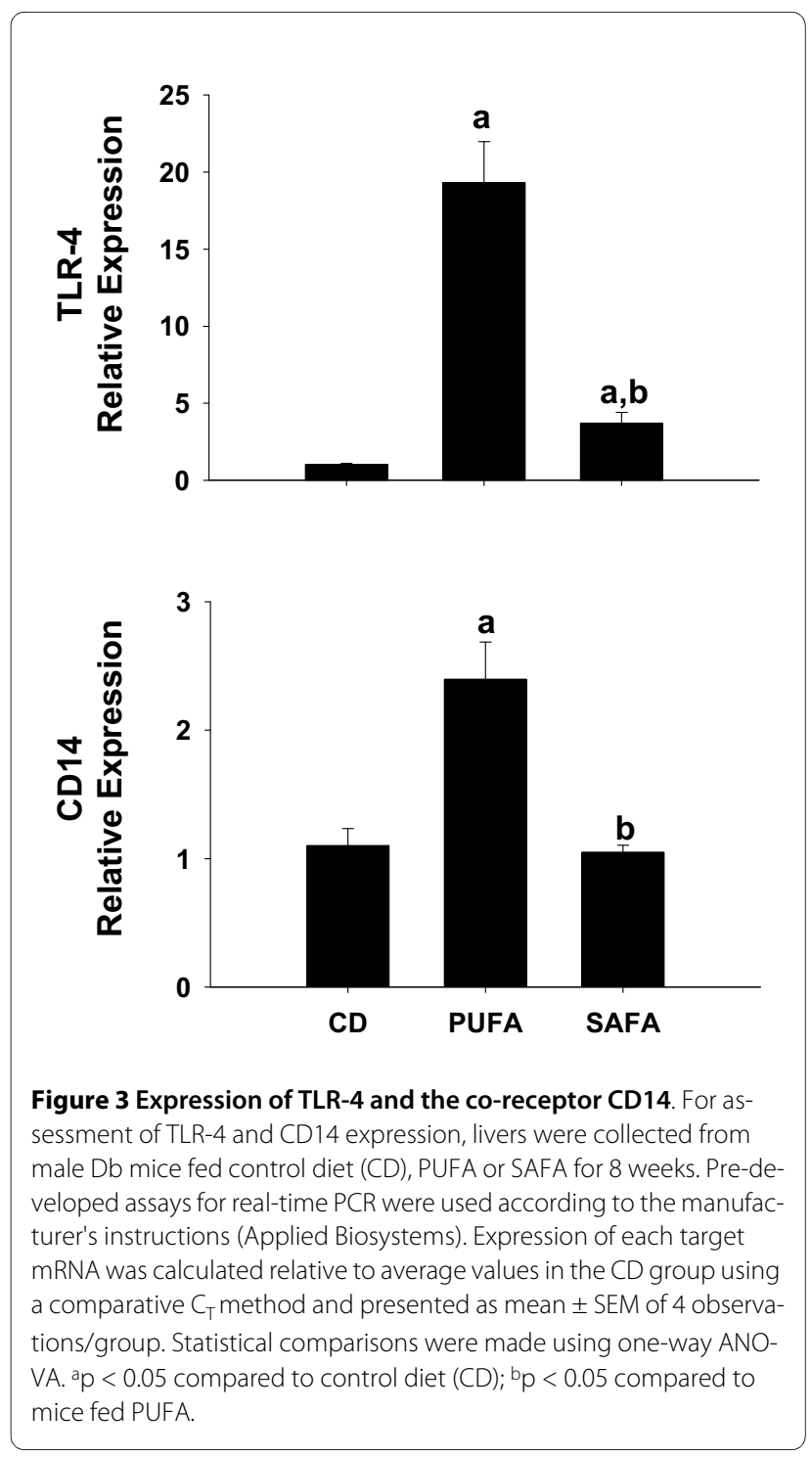

and CD14. Compared to wild type mice, a significant increase in TLR-4 expression was observed in TLR-2 ${ }^{-1}$ mice fed PUFA or SAFA (Fig. 8). Expression of the TLR-4 co-receptor CD14 was also increased significantly by 2fold and 4-fold, respectively, in TLR-2/- mice fed PUFA or SAFA when compared to diet-matched wild type mice (Fig. 8).

\section{Expression of inflammatory and fibrosis markers correlate} with toll-like receptor-4 and CD14

The relationship between expression of TLR-4 signalling pathway components (i.e. TLR- 4 and CD-14) and markers of inflammation and fibrosis was assessed using the Pearson's product moment statistical test. For this purpose, data from wild type and TLR-2/- mice fed PUFA were compiled. As shown in Figure 9, a significant positive correlation exists between the expression of TNF- $\alpha$, and each of the TLR-4 signalling components. Feeding 


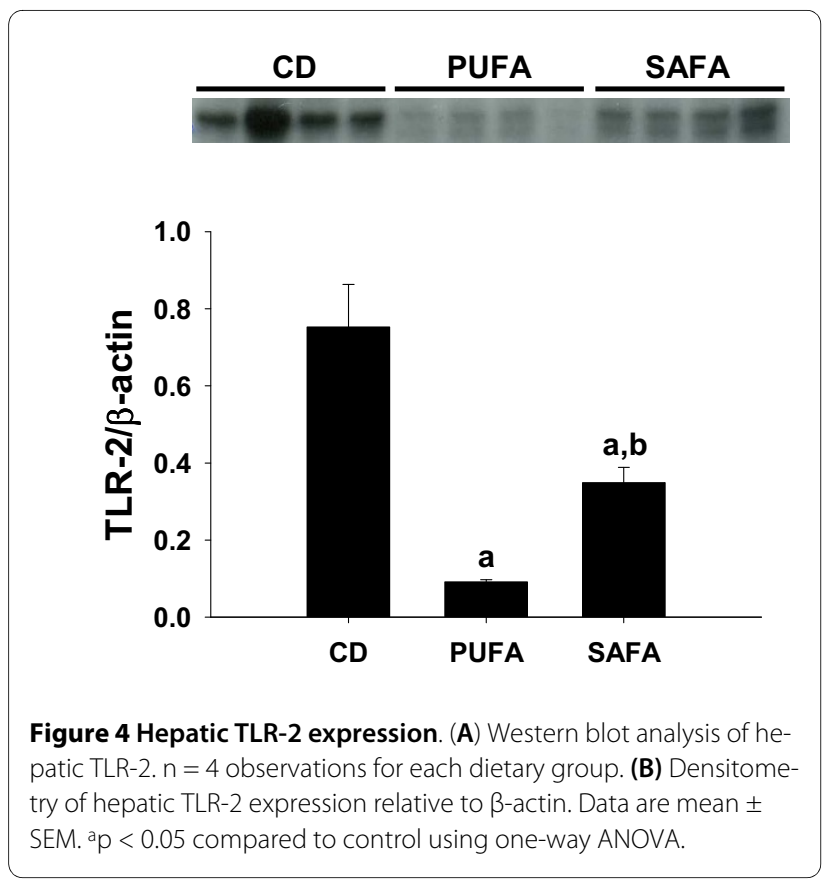

PUFA to both mouse strains also resulted in a significant positive correlation between TLR-4, CD14 and the expression of the matrix protein collagen $\alpha 1$ (Fig. 10). Similar results were obtained in wild type and TLR-2-/mice fed SAFA (data not shown).

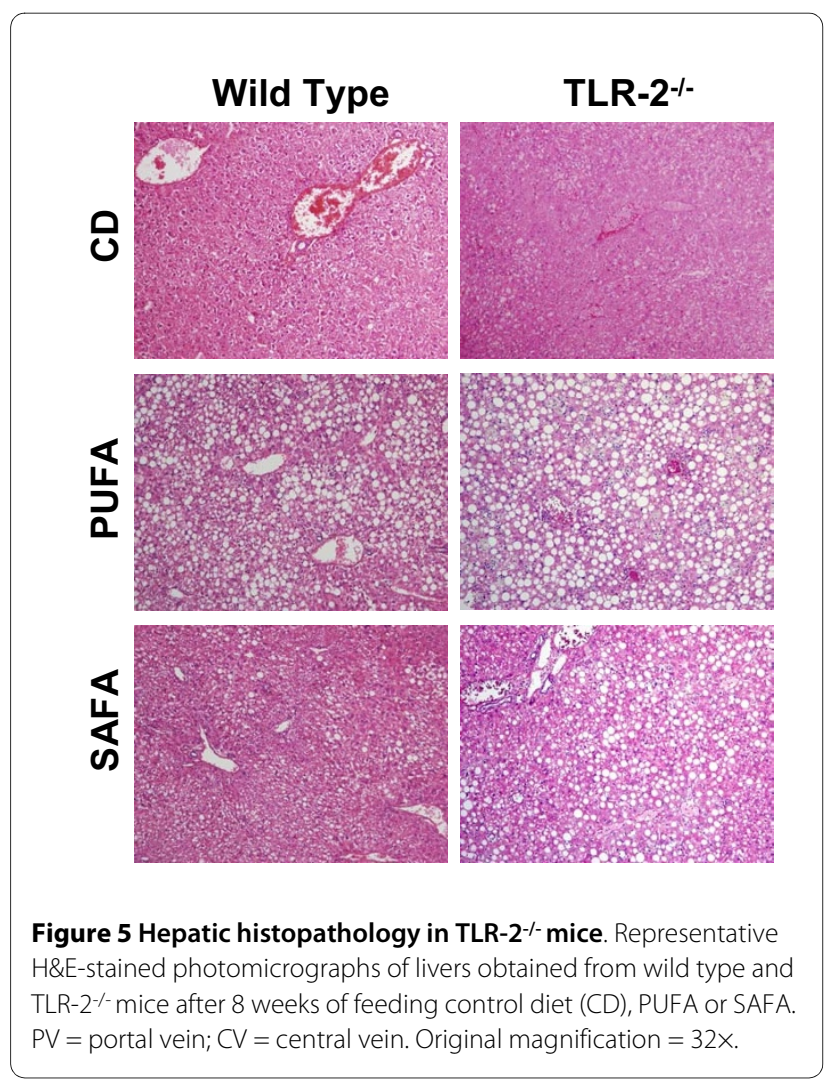

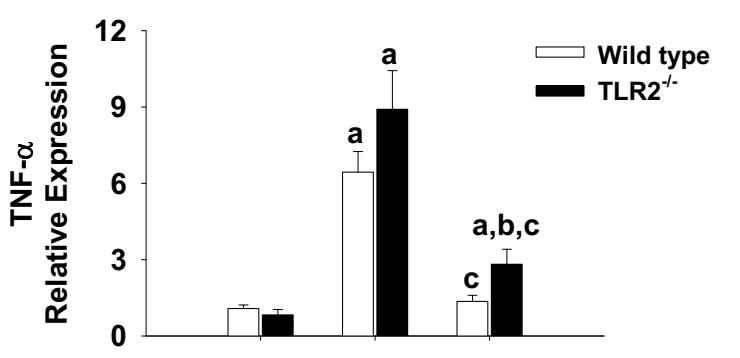

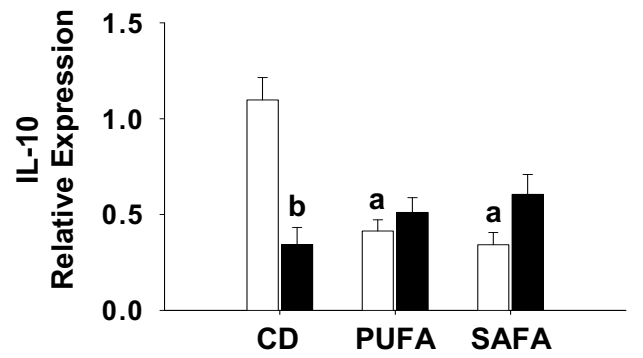

Figure 6 Hepatic TNF-a and IL-10 mRNA levels in TLR-2-- mice. EXpression of TNF-a and IL-10 mRNA was analyzed by real-time PCR and calculated relative to average values in the control group using a comparative $C_{T}$ method. Data are presented as mean \pm SEM of 5 observations/group. Statistical comparisons were made using two-way ANOVA and Tukey multiple comparisons test. ap $<0.05$ compared to strain-matched mice fed control diet (CD); $b p<0.05$ compared to dietmatched wild type (WT) mice; ${ }^{c} p<0.05$ compared to strain-matched mice fed PUFA.

\section{Discussion}

A positive correlation exists between the incidence of metabolic syndrome and the amount of total fat consumed in the diet of obese humans. In the setting of obesity, endothelial dysfunction precedes the clinical manifestation of co-morbid diseases such as cardiovascular disease [21]. In contrast to the protective effects of unsaturated fat, feeding a diet rich in saturated fatty acids was shown to impair endothelial function as indicated by flow-mediated vasodilation, and stimulated inflammation as evidenced by increased P-selectin expression [22]. Although diet is known to contribute significantly to the genesis of cardiovascular disease, less is known about the influence of diet on the development of NASH. Thus, the goal of the first set of experiments described herein was to determine the effect of the quality of dietary fat on the extent of NASH. To this end, mice were fed a methionineand choline-deficient diet that was enriched either in corn oil (PUFA) or coconut oil (SAFA). Because obese people in western cultures where liver disease is prevalent typically consume a diet that contains high amounts of saturated fat, we hypothesized that mice consuming SAFA would exhibit the greatest degree of NASH. Contrary to this hypothesis, histological and molecular evi- 

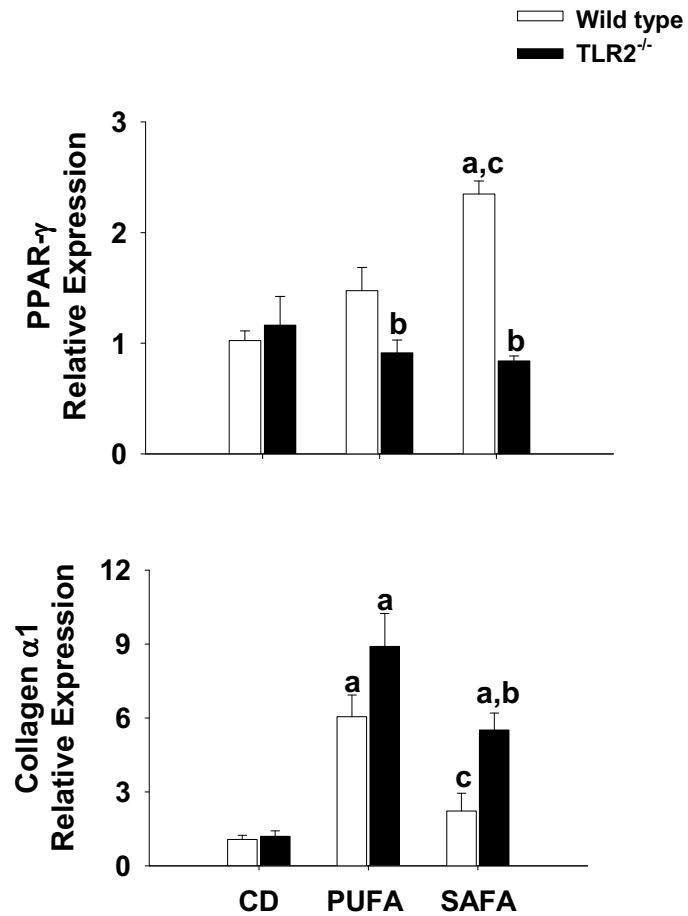

Figure 7 Hepatic PPAR- $\gamma$ and collagen a 1 mRNA levels in TLR-2-mice. Expression of PPAR- $\gamma$ and Collagen a1 mRNA was analyzed by real-time PCR and calculated relative to average values in the control group using a comparative $C_{T}$ method. Data are presented as mean \pm SEM of 5 observations/group. Statistical comparisons were made using two-way ANOVA and Tukey multiple comparisons test. ap $<0.05$ compared to strain-matched mice fed control diet $(C D)$; $b p<0.05$ compared to diet-matched wild type (WT) mice; $c p<0.05$ compared to strain-matched mice fed PUFA.

dence of NASH was significantly attenuated in this dietary group. These findings are similar to the reported influence of diet in rodent models of alcoholic steatohepatitis (ASH). For example, development of significant ASH in rodents requires the addition of polyunsaturated fatty acid to the ethanol-containing diet [23]. Nanji et al. (1989) were among the first to report that ethanol-containing diets high in saturated fat blunted the progression of ASH $[11,24,25]$. Moreover, saturated fat was shown to reverse fibrotic lesions that developed in late stages of ASH $[25,26]$.

The protective effects of feeding a high saturated fat diet during ethanol exposure are believed to be mediated by adiponectin [27]. In fact, inclusion of purified saturated fatty acids in the culture medium of ethanol-treated 3T3 L1 adipocytes enhanced adiponectin promoter activity as well as expression, demonstrating a role for saturated fat in the production of this anti-inflammatory hormone [27]. Here, we show that feeding SAFA blunted
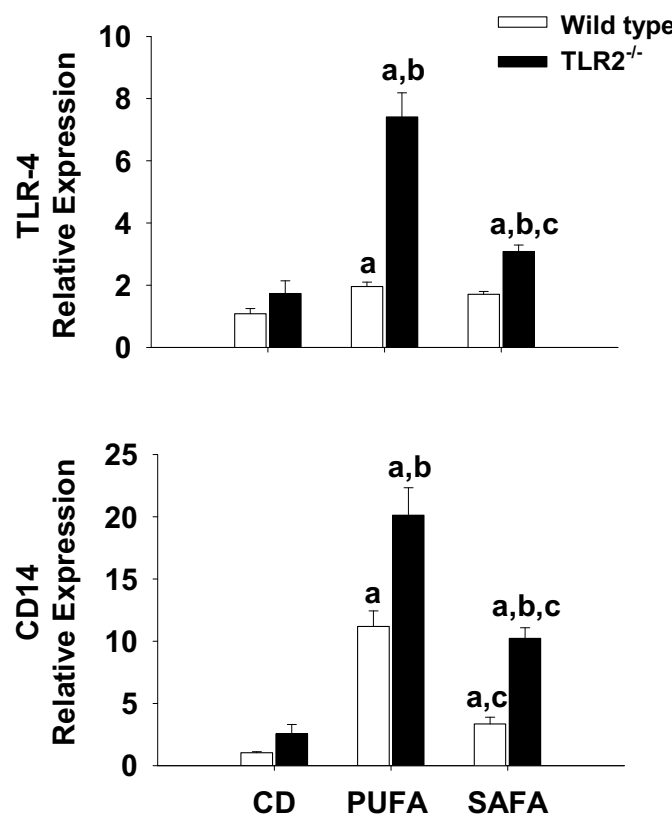

Figure 8 Expression of TLR-4 associated signaling molecules. For assessment of TLR-4 and CD14 expression, livers were collected from male C57BL/ 6 and TLR-2-- mice fed CD or MCDD for 8 weeks. Pre-developed assays for real-time PCR were used according to the manufacturer's instructions. Expression of each target mRNA was calculated relative to average values in the control group using a comparative $C_{T}$ method and presented as mean \pm SEM of at least 4 observations/ group. Statistical comparisons were made using two-way ANOVA and Tukey multiple comparisons test. ap $<0.05$ compared to strainmatched mice fed control diet (CD); $b p<0.05$ compared to dietmatched wild type (WT) mice; ${ }^{c} p<0.05$ compared to strain-matched mice fed PUFA.

increases in TLR-4 and CD14 expression in wild type mice, which is likely an additional protective benefit of high saturated dietary fat. The influences of fats in vivo are in stark contrast to the effects of fatty acids in vitro. For example, the major $\omega-3$ unsaturated fatty acids found in fish oil eicosapentaenoic acid (EPA) and docosahexaenoic acid (DHA) blunted the inflammatory phenotype that results from the exposure of various human and murine cell lines to TLR-4 or TLR-2 agonists [8-11]. On the other hand, saturated fatty acids stimulated NFkB promoter activity and a pro-inflammatory phenotype [10]. It should be noted that these in vitro studies relied on the ectopic expression of TLRs; therefore, studies in cultured cells may not be representative of endogenous TLR responses in the setting of NASH.

In addition to diminished TLR-4 signalling components, feeding SAFA enhanced the expression of TLR-2 relative to the PUFA-fed mice. Therefore, the next experimental series examined the influence of TLR-2 deficiency on NASH pathogenesis. Despite partially overlapping 


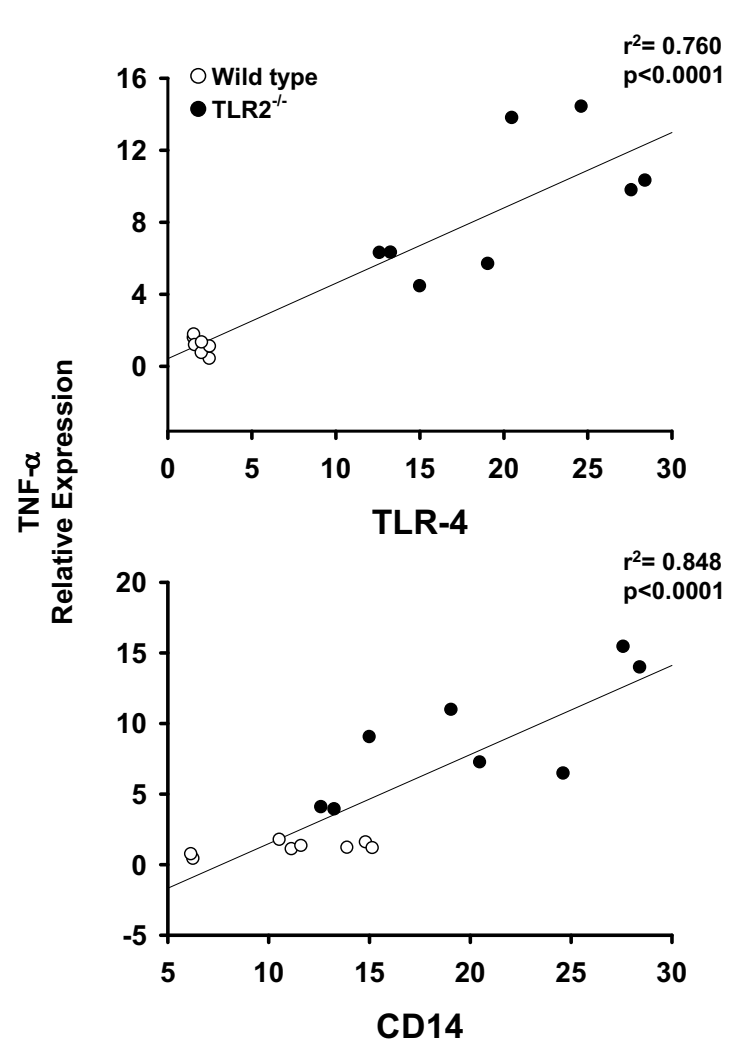

Figure 9 Toll-like receptor- 4 expression correlates with mRNA levels of TNF-a. Real-time PCR data for TLR-4 and CD-14 were compared with the expression of the inflammation marker TNF-a using the Pearson's product moment statistical test. Each figure contains the compiled data from wild type and TLR-2-/-mice fed PUFA. Correlation coefficients ( $p$ ) and regression analysis $\left(r^{2}\right)$ are presented with each figure.

ligand specificities and signalling pathways with TLR-4, data presented herein indicate that TLR-2 may play a protective role against the induction of steatohepatitis. Indeed, histological and molecular evidence of NASH were significantly enhanced in TLR-2-- mice relative to wild type mice, an effect most pronounced in mice fed SAFA. These current findings are consistent with a previous study by Szabo et al. that demonstrated enhanced sensitivity of TLR-2-- to NASH [28]. Compared to wild type mice, ALT was enhanced in TLR- $2^{-/}$mice fed MCDD. Moreover, wild type mice with MCDD-induced NASH were more sensitive to the TLR-4 ligand lipopolysaccharide, but not TLR-2 ligands. Taken together with our present findings, these studies suggest that expression of TLR-2 plays a protective role against NASH pathogenesis. On the other hand, it must also be noted that the augmented injury in TLR- $2^{-1-}$ mice reported herein was associated with enhanced expression of TLR-4 as well as the adaptor molecule CD-14. In fact, a significant positive correlation was found between elements of

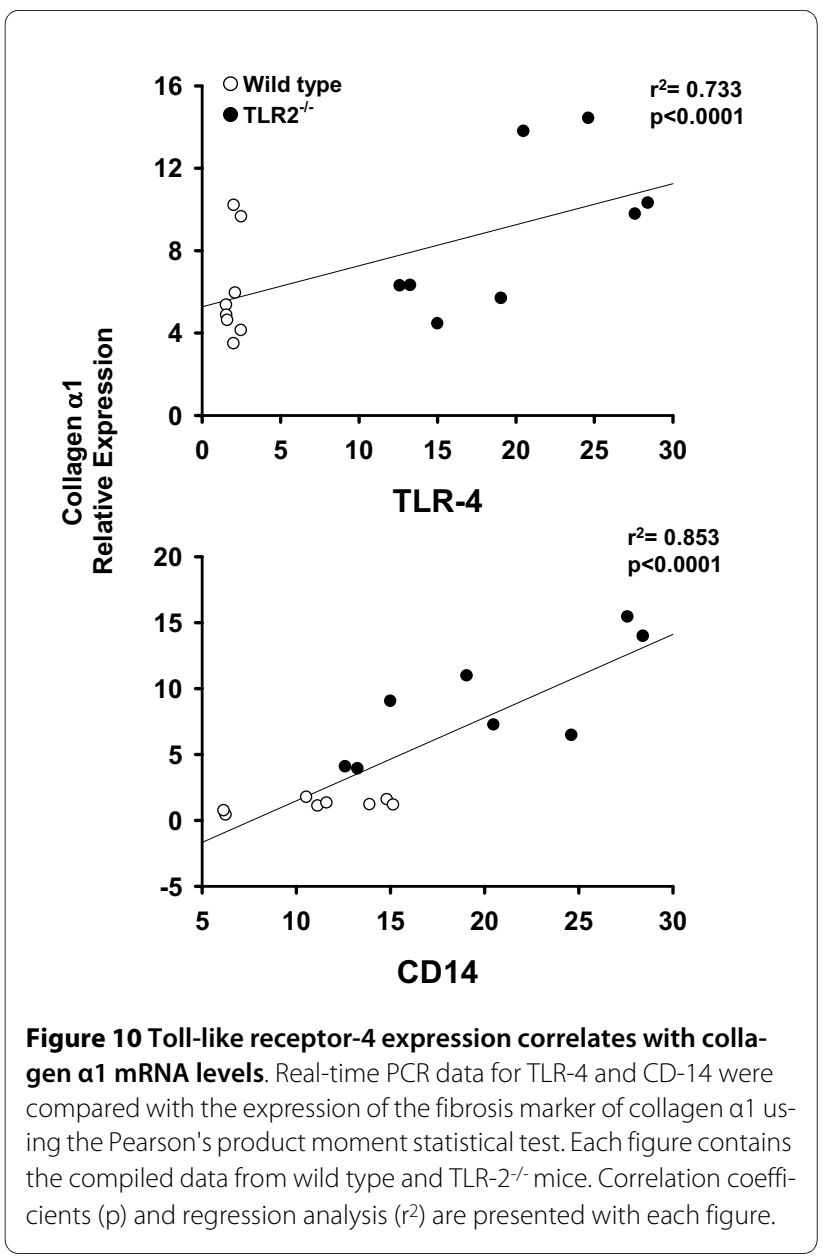

the TLR-4 pathway and the expression of pro-inflammatory and pro-fibrogenic mediators.

Injury observed using the MCDD dietary model of steatohepatitis is reportedly associated with increased intestinal permeability and the enhanced presence of endotoxin in the portal blood supply [14,29]. Previous findings using murine models of exposure to enteric bacterial pathogens and chemically-induced colitis indicated that TLR-2 plays a critical role in the maintenance of mucosal integrity. For example, Cario et al. demonstrated that stimulation of intestinal epithelial cells with a TLR-2 agonist preserved barrier function whereas mice deficient in TLR-2 expression exhibited disruptions in tight junctional complexes. Although not tested directly, these findings suggest that TLR-2 deficiency has the potential to augment steatohepatitis via promoting the escape of endogenous bacterial pathogens, which activate the TLR4 signalling pathway.

In support of the idea that diets enriched in saturated fatty acid directly influence the fibrogenic response, Abergel et al. reported that exposure of stellate cells to palmitic acid significantly blunted transformation and the potential to produce matrix proteins such as type I colla- 
gen [30]. The response of stellate cells to saturated fatty acid was believed to be mediated via PPAR- $\gamma$. In fact, over-expression of this nuclear receptor prevented phenotypic transformation and production of collagen by stellate cells. We showed recently that feeding a high fat (coconut oil) diet to mice for 3 weeks enhanced PPAR- $\gamma$ expression in the liver [31]. In the present study SAFA enhanced PPAR- $\gamma$ expression in wild type mice, a phenomenon that was prevented in TLR-2-- mice. Moreover, an inverse relationship between the expression of collagen $\alpha 1$ and PPAR- $\gamma$ in mice fed SAFA was observed. Thus, our finding of blunted PPAR- $\gamma$ expression in livers of TLR-2 $\%$ mice suggests that this receptor plays a role in the induction of PPAR- $\gamma$ in response to dietary saturated fat.

\section{Conclusions}

Enrichment of the MCDD diet with saturated fat blunted NASH pathogenesis in wild type mice. The protective effects of saturated fat were less pronounced in mice deficient in TLR-2 expression, demonstrating the role of innate immunity in the response to the type of fat supplied in the diet. Clearly, more work is needed to understand mechanisms underlying this complex relationship between liver pathology and quality of dietary fat.

\section{Competing interests}

The authors declare that they have no competing interests.

\section{Authors' contributions}

CAR: Contributed the conceptual design, data acquisition, analysis and interpretation; was involved in manuscript preparation and has consented to the publication of this manuscript. LG: Contributed toward data acquisition, analysis and interpretation; was involved in manuscript preparation and has consented to the publication of this manuscript. MA: Contributed toward data acquisition, analysis and interpretation; was involved in manuscript preparation and has consented to the publication of this manuscript. JP: Contributed toward data acquisition, analysis and interpretation; was involved in manuscript preparation and has consented to the publication of this manuscript. KB: Contributed toward data acquisition, analysis and interpretation; was involved in manuscript preparation and has consented to the publication of this manuscript. PA: Contributed toward data acquisition, analysis and interpretation; was involved in manuscript preparation and has consented to the publication of this manuscript. KP: Contributed the conceptual design, data acquisition, analysis and interpretation; was involved in manuscript preparation and has consented to the publication of this manuscript.

\section{Acknowledgements}

We would like to express sincere gratitude to A. Akira (Tokyo, Japan) for the generous gift of the TLR-2-/-mice. This work was supported in part by federal funds from: CAR: National Heart Lung and Blood Institutes and the NHLBI (1K01HL084723-01); National Institute of Diabetes and Digestive and Kidney Diseases (3P01DK43785-13S1).

\section{Author Details}

'Department of Molecular and Cellular Physiology, Louisiana State University Health Sciences Center, Shreveport, LA USA and 2Department of Pathology, Louisiana State University Health Sciences Center, Shreveport, LA USA

Received: 25 October 2009 Accepted: 28 May 2010

Published: 28 May 2010

\section{References}

1. Tarantino G, Saldalamacchia G, Conca P, Arena A: Non-alcoholic fatty liver disease: further expression of the metabolic syndrome. J Gastroenterol Hepatol 2007, 22:293-303.

2. Dall TM, Fulgoni VL III, Zhang Y, Reimers KJ, Packard PT, Astwood JD: Potential health benefits and medical cost savings from calorie, sodium, and saturated fat reductions in the American diet. Am J Health Promot 2009, 23:412-422.

3. Lopez S, Bermudez B, Pacheco YM, Villar J, Abia R, Muriana FJ: Distinctive postprandial modulation of $\{$ beta\} cell function and insulin sensitivity by dietary fats: monounsaturated compared with saturated fatty acids. Am J Clin Nutr 2008, 88:638-644.

4. Lichtenstein AH, Kennedy E, Barrier P, Danford D, Ernst ND, Grundy SM, Leveille GA, Van HL, Williams CL, Booth SL: Dietary fat consumption and health. Nutr Rev 1998, 56:S3-19.

5. Kim F, Pham M, Maloney E, Rizzo NO, Morton GJ, Wisse BE, Kirk EA, Chait A, Schwartz MW: Vascular inflammation, insulin resistance, and reduced nitric oxide production precede the onset of peripheral insulin resistance. Arterioscler Thromb Vasc Biol 2008, 28:1982-1988.

6. West NA, Hamman RF, Mayer-Davis EJ, D'Agostino RB Jr, Marcovina SM, Liese AD, Zeitler PS, Daniels SR, Dabelea D: Cardiovascular risk factors among youth with and without type 2 diabetes: differences and possible mechanisms. Diabetes Care 2009, 32:175-180.

7. Musso G, Gambino R, De MF, Cassader M, Rizzetto M, Durazzo M, Faga E, Silli B, Pagano G: Dietary habits and their relations to insulin resistance and postprandial lipemia in nonalcoholic steatohepatitis. Hepatol 2003, 37:909-916.

8. Lee JY, Plakidas A, Lee WH, Heikkinen A, Chanmugam P, Bray G, Hwang $\mathrm{DH}$ : Differential modulation of Toll-like receptors by fatty acids: preferential inhibition by $n-3$ polyunsaturated fatty acids. J Lipid Res 2003, 44:479-486.

9. Li H, Ruan XZ, Powis SH, Fernando R, Mon WY, Wheeler DC, Moorhead JF Varghese $Z$ : EPA and DHA reduce LPS-induced inflammation responses in HK-2 cells: evidence for a PPAR-gamma-dependent mechanism. Kidney Int 2005, 67:867-874.

10. Lee JY, Ye J, Gao Z, Youn HS, Lee WH, Zhao L, Sizemore N, Hwang DH: Reciprocal modulation of Toll-like receptor-4 signaling pathways involving MyD88 and phosphatidylinositol 3-kinase/AKT by saturated and polyunsaturated fatty acids. J Biol Chem 2003, 278:37041-37051.

11. Weatherill AR, Lee JY, Zhao L, Lemay DG, Youn HS, Hwang DH: Saturated and polyunsaturated fatty acids reciprocally modulate dendritic cell functions mediated through TLR4. J Immunol 2005, 174:5390-5397.

12. Kougias $P$, Chai $H$, Lin PH, Yao Q, Lumsden AB, Chen C: Effects of adipocyte-derived cytokines on endothelial functions: implication of vascular disease. J Surg Res 2005, 126:121-129.

13. Maloney E, Sweet IR, Hockenbery DM, Pham M, Rizzo NO, Tateya S, Handa P, Schwartz MW, Kim F: Activation of NF-\{kappa\}B by Palmitate in Endothelial Cells: A Key Role for NADPH Oxidase-Derived Superoxide in Response to TLR4 Activation. Arterioscler Thromb Vasc Biol 2009, 29:1370-1375

14. Rivera CA, Adegboyega P, van Rooijen N, Tagalicud A, Allman M, Wallace $\mathrm{M}$ : Toll-like receptor-4 signaling and Kupffer cells play pivotal roles in the pathogenesis of non-alcoholic steatohepatitis. J Hepatol 2007, 47:571-579

15. Takeuchi O, Sato S, horiuchi T, Hoshino K, Takeda K, Dong Z, Modlin RL, Akira S: Cutting edge: role of Toll-like receptor 1 in mediating immune response to microbial lipoproteins. J Immunol 2002, 169:10-14.

16. Hoebe K, Georgel P, Rutschmann S, Du X, Mudd S, Crozat K, Sovath S, Shamel L, Hartung T, Zahringer U, Beutler B: CD36 is a sensor of diacylglycerides. Nature 2005, 433:523-527

17. McCuskey RS, Ito Y, Robertson GR, McCuskey MK, Perry M, Farrell GC: Hepatic microvascular dysfunction during evolution of dietary steatohepatitis in mice. Hepatol 2004, 40:386-393.

18. Kirsch R, Clarkson V, Shephard EG, Marais DA, Jaffer MA, Woodburne VE, Kirsch RE, Hall PL: Rodent nutritional model of non-alcoholic steatohepatitis: species, strain and sex difference studies. $J$ Gastroenterol Hepatol 2003, 18:1272-1282.

19. Sahai A, Malladi P, Pan X, Paul R, Melin-Aldana H, Green RM, Whitington PF: Obese and diabetic $\mathrm{db} / \mathrm{db}$ mice develop marked liver fibrosis in a model of nonalcoholic steatohepatitis: role of short-form leptin receptors and osteopontin. Am J Physiol Gastrointest Liver Physiol 2004 287:G1035-G1043 
20. Rivera CA, Abrams SH, Tcharmtchi MH, Allman M, Ziba TT, Finegold MJ, Smith CW: Feeding a corn oil/sucrose-enriched diet enhances steatohepatitis in sedentary rats. Am J Physiol Gastrointest Liver Physiol 2006, 290:G386-G393.

21. Anderson TJ, Gerhard MD, Meredith IT, Charbonneau F, Delagrange D, Creager MA, Selwyn AP, Ganz P: Systemic nature of endothelial dysfunction in atherosclerosis. Am J Cardiol 1995, 75:71B-74B.

22. Keogh JB, Grieger JA, Noakes M, Clifton PM: Flow-mediated dilatation is impaired by a high-saturated fat diet but not by a high-carbohydrate diet. Arterioscler Thromb Vasc Biol 2005, 25:1274-1279.

23. Nanji AA, French SW: Dietary linoleic acid is required for development of experimentally induced alcoholic liver injury. Life Sci 1989, 44:223-227.

24. Nanji AA, Mendenhall CL, French SW: Beef fat prevents alcoholic liver disease in the rat. Alcohol Clin Exp Res 1989, 13:15-19.

25. Nanji AA, Zakim D, Rahemtulla A, Daly T, Miao L, Zhao S, Khwaja S, Tahan SR, Dannenberg AJ: Dietary saturated fatty acids down-regulate cyclooxygenase- 2 and tumor necrosis factor alfa and reverse fibrosis in alcohol-induced liver disease in the rat. Hepatol 1997, 26:1538-1545.

26. Nanji AA, French SW: Dietary factors and alcoholic cirrhosis. Alcohol Clin Exp Res 1986, 10:271-273.

27. You M, Considine RV, Leone TC, Kelly DP, Crabb DW: Role of adiponectin in the protective action of dietary saturated fat against alcoholic fatty liver in mice. Hepatol 2005, 42:568-577.

28. Szabo G, Velayudham A, Romics L Jr, Mandrekar P: Modulation of nonalcoholic steatohepatitis by pattern recognition receptors in mice: the role of toll-like receptors 2 and 4. Alcohol Clin Exp Res 2005, 29:140S-145S

29. Brun P, Castagliuolo I, Di LV, Buda A, Pinzani M, Palu' G, Martines D: Increased intestinal permeability in obese mice: new evidences in the pathogenesis of nonalcoholic steatohepatitis. Am J Physiol Gastrointest Liver Physiol 2006, 22:293-303.

30. Abergel A, Sapin V, Dif N, Chassard C, Darcha C, Marcand-Sauvant J, Gaillard-Martinie B, Rock E, Dechelotte P, Sauvant P: Growth arrest and decrease of alpha-SMA and type I collagen expression by palmitic acid in the rat hepatic stellate cell line PAV-1. Dig Dis Sci 2006, 51:986-995.

31. Allman M, Gaskin L, Rivera CA: CCl4-induced hepatic injury in mice fed a wstern diet is associated with blunted healing. J Gastroenterol Hepatol 2010, 25:635-643.

\section{Pre-publication history}

The pre-publication history for this paper can be accessed here: http://www.biomedcentral.com/1471-230X/10/52/prepub

\section{Submit your next manuscript to BioMed Centra} and take full advantage of:

- Convenient online submission

- Thorough peer review

- No space constraints or color figure charges

- Immediate publication on acceptance

- Inclusion in PubMed, CAS, Scopus and Google Scholar

- Research which is freely available for redistribution

Submit your manuscript at www.biomedcentral.com/submit
C Biomed Central 